Servicio de publicaciones y difusión científica (SPDC), Universidad de Las Palmas de Gran Canaria, Parque CientíficoTecnológico, Edificio Polivalente II, C/ Practicante Ignacio Rodríguez, s/n Campus Universitario de Tafira 35017 - Las Palmas de Gran Canaria, Spain.

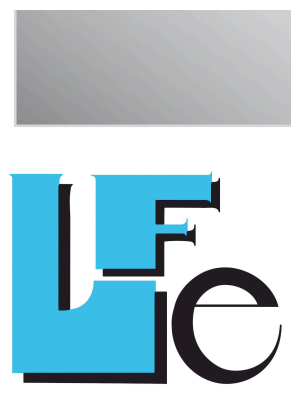

Revista de Lenguas para Fines

Específicos

\section{Revista de lenguas} para fines específicos

eISSN: 2340-8561

Journal information, indexing and abstracting details, archives, and instructions for submissions:

https://ojsspdc.ulpgc.es/ojs/index.php/LFE/index

\section{Tense and agreement markers} in the interlanguage of Spanish learners of English

\section{Jose Medina}

Universidad de Las Palmas de Gran Canaria, Departamento de Didácticas Especiales. Facultad de Ciencias de la Educación. C/ Pérez del Toro, s/n 35004 Las Palmas de Gran Canaria (Spain).

Article first published online: 27 July 2015.

Article published online with DOI added: 5 April 2016

Revista de Lenguas para fines específicos is licensed under a Creative Commons ReconocimientoNoComercial-SinObraDerivada 4.0 Internacional License. 


\title{
Tense and agreement markers in the interlanguage of Spanish learners of English
}

\author{
Jose Medina ${ }^{1}$ \\ Universidad de Las Palmas de Gran Canaria/ \\ Humboldt-Universität zu Berlin
}

\begin{abstract}
This paper presents an analysis of the learning process of the features of tense and agreement in the interlanguage system of L1 Spanish speakers learning L2 English. This study uses a statistically significant sample of the student population in year 6 of primary education (11-12 years old), year 4 of secondary education (15-16 years old) and upper sixth form (17-18 years old), in the Autonomous Region of the Canary Islands. The research instrument was their written production. The analysis conducted includes the bound morphemes -ed and -s and the free morpheme be (with both copular and auxiliary function). The results show a predominant omission for the agreement morpheme $-s$ in the three groups in which the corpus has been divided. On the other hand, the bound morpheme -ed and the free morpheme be present the highest percentage of correct use. These results confirm the capacity of the subjects to learn the verb features of tense and agreement, thus supporting the arguments of the Missing Surface Inflection Hypothesis (Prévost and White, 2000). As the results for the bound morphemes are not in agreement, the influence of other factors on the good results of the bound morpheme -ed, such as the verb aspect or the absence of phonological realizations, is suggested.
\end{abstract}

Keywords: L2 English, written production, tense; agreement

1 Corresponding author - Universidad de Las Palmas de Gran Canaria, Departamento de Didácticas Especiales. Facultad de Ciencias de la Educación. C/ Pérez del Toro, s/n 35004 Las Palmas de Gran Canaria (Spain).

Email: jose.medina@ulpgc.es 


\section{RESUMEN}

Este artículo presenta un análisis del proceso de aprendizaje de los rasgos de tiempo y concordancia verbales en el sistema de interlengua de hablantes de español (L1) y aprendices de inglés (L2). En la investigación llevada a cabo se ha utilizado una muestra estadísticamente significativa de la población estudiantil perteneciente al sexto curso de educación primaria (11-12 años de edad), cuarto curso de educación secundaria (15-16 años de edad) y segundo de bachillerato (17-18 años de edad) de la Comunidad Autónoma de las Islas Canarias. El instrumento utilizado para la investigación fue su producción escrita. Se analizaron los morfemas ligados -ed y -s y el morfema libre be (tanto con función copulativa como auxiliar). Los resultados muestran una predominancia de la omisión para el morfema de concordancia verbal $-s$ en los tres grupos que conforman el corpus. Por otro lado, el morfema ligado -ed y el morfema be presentan el mayor porcentaje de uso correcto. Estos resultados confirman la capacidad de los sujetos para aprender los rasgos de tiempo y concordancia verbales, apoyando de esta forma los argumentos de la Hipótesis de la Inflexión Superficial Ausente (HISA) (Prévost y White, 2000). Puesto que los resultados de los morfemas ligados no concuerdan, se sugiere la influencia de otros factores en los buenos resultados obtenidos con el morfema ligado -ed, tales como el aspecto verbal o la ausencia de realizaciones fonológicas.

Palabras clave: inglés L2, producción escrita, tiempo verbal, concordancia

\section{Introduction}

There have been several studies researching the acquisition of verbal morphemes in L2 learners of English. Some of these have focused on the acquisition of these morphemes in native Spanish speakers. Notwithstanding, unlike them, this study addresses this phenomenon using a statistically significant sample from a specific population. Additionally, this research covers three different educational stages. This entails an analysis of the learning process of subjects from different ages and going through different learning levels at the time of the analysis. These two innovative aspects make a significant contribution to the field of SLA studies.

In the analysis of the acquisition process of an L2, Selinker described an autonomous linguistic system different from the L1 and the L2 and which he placed between both of them:

[...] in the making of constructs relevant to a theory of second-language learning, one would be completely justified in hypothesizing, perhaps even compelled to hypothesize, the existence of a separate linguistic system based on the observable output which results from a learner's attempted production of a TL norm. This linguistic system we will call 'interlanguage' (IL) (1972, p.214). 
In the present study, the approach to the L2 learning process of Spanish speakers follows Selinker's idea of an IL system. Therefore, the description of linguistic features regarding the production of these learners would be framed in such system. Particularly, the main aim of this study is to analyse the functional category of Inflection with the intention of establishing the success (or its absence) of the learning process. For this, the focus will be placed on the grammatical morphemes marking past tense (-ed) and agreement (-s), as well as the verb be.

Albright and Hayes (2003) refer to a process of generalization which leads to a system of rules in the acquisition of the past morpheme -ed. The learner will generalize the use of this morpheme until s/he learns the rule to be followed when using this marker. However, during this process there will be an alternation of both inflections and omissions of inflections, not only when marking past contexts (-ed), but also agreement (-s) (Hawkins and Casillas, 2008; Ionin and Wexler, 2002; Paradis, 2010).

Paradis (2008) mentions that the analysis of the tense marker (a parameter closely related to the functional category of Inflection) is a valid tool to determine the process of language acquisition (L1 and L2). Therefore, a positive result in the acquisition of this parameter would mean a satisfactory learning process of a language.

Nonetheless, according to Meisel $(1991,1997)$ and Clahsen (1988) the acquisition of a functional category is not possible by an L2 learner. These authors support the Impairment Hypothesis $(\mathrm{IH})$, which postulates that, unlike an L1 learner, an L2 learner will not be able to acquire functional categories. According to this hypothesis, the learner would not be able to access the UG and would make mistakes both with inflected and non-inflected forms. However, it is rare the use of an inflected form in the place of a non-inflected form by an L2 learner. What is more, as Prèvost and White (2000, p.127) claim, the L2 learners "have abstract features for finiteness and agreement in their interlanguage representation, as evidenced by the syntactic and morphological behaviour of finite verbs". These authors explain in their Missing Surface Inflection Hypothesis (MSIH) that the problems that L2 learners find in the realization of the verbal morphemes do not show an impairment for the acquisition of the functional category of Inflection, but problems with the resetting of parameters. This, unlike the $\mathrm{IH}$, would support the access to the UG by the $\mathrm{L} 2$ learner.

Therefore, tense could be used, following Paradis (2008), as a measure and descriptor of the learning process if the results agreed on the MSIH. If, on the other hand, the results supported the $\mathrm{IH}$, it would not be possible to establish a qualitative description of the learning process using tense as a marker. The conditions to 
support the MSIH will be given by the alternation and predominance of inflected and uninflected forms and their distribution in the IL system of the L2 learners, as well as the presence of free morphemes marking agreement correctly.

Regarding the order of acquisition of the morphemes in English (L2), Zobl and Liceras (1994) presented a series of classifications which show that the acquisition of the free verb morphemes (verb be) is previous to the acquisition of the bound morphemes (-s. $-e d)$. All the classifications analysed by these authors agree on the acquisition of the copular be first, followed by the verb be with an auxiliary function. The bound morphemes -ed and -s, on the other hand, would be acquired later.

One of the classifications to which these authors refer was done by Andersen (1978), in relation with the order of acquisition of these four morphemes by Spanish native speakers. He also presents the copular be as the first in the acquisition process, followed by the auxiliary be, the bound morpheme -ed and finally the -s morpheme.

Therefore, following the previous arguments, this study poses the following questions as the ones to be answered:

- Do the values obtained for the use of tense and agreement markers reflect a positive learning process of these verb features?

- Are the free morphemes (verb be) acquired before the bound morphemes (-s, -ed)?

- Do the results obtained agree with the MSIH or with the $\mathrm{IH}$ ?

\section{Method}

Different factors related to the state of the art were taken into account when choosing the material and subjects for this analysis. The research conducted on the omission of verbal inflections and the acquisition of the verbal morphemes in the oral production of English (L2) learners is extensive (Hawkins and Casillas, 2008; Haznedar, 2003; Hsieh, 2009; Ionin and Wexler, 2002; Muftah and Eng, 2011; Paradis, 2008, 2010; Paradis et al., 2008; Prévost and White, 2000; White, 2003). Nevertheless, the study of those verbal structures in the written production is scarce (Kim, 2011; Salaberry, 2000). This study has used the written production as research instrument.

Moreover, none of the studies mentioned before used a significant sample of a specific population. They conducted their research with subjects ranging from one (White, 2003) to 77 (Muftah and Eng, 2011). In an attempt to obtain more quantitatively solid results, a considerably larger number of students in the sample has been included in this research. 


\subsection{Population of study and sample}

The election of a significant sample allows the inference of properties of a whole population. As this research aims at determining the learning process in the education system of the Canary Islands, the subjects chosen belong to all the seven islands which conform this region. More specifically, it includes a representative sample of the written production of 6167 students from three different educational stages:

- 1521 students of the sixth year of Primary Education aged 11-12 years old

- 2706 students of the fourth year of Secondary Education aged 15-16 years old

- 1940 students of the second year of the sixth form aged 17-18 years old

The minimum size of the sample has been calculated so that the results of the study would be significant and generalizable according to the specified margin of error (Neuber, 1980, p. 48-49). For this purpose, this study has applied the formula established to calculate the size of samples taken from finite populations (García Ferrando, 1985, p.142):

$$
\mathrm{n}=\frac{\mathrm{z}^{2} \times \mathrm{N} \times \mathrm{p} \times \mathrm{q}}{\mathrm{N} \times \mathrm{E}^{2}+\mathrm{z}^{2} \times \mathrm{p} \times \mathrm{q}}
$$

Thus, assuming the work with an error $\mathrm{E}=0,05$, to a level of significance of 0,05 ( $95 \%$, which corresponds to 2 sigmas, $z=2$ ) and in the most unfavorable possible case $(p=0,5$ and $q=0,5)$, this formula will indicate the theoretical size $(n)$ which must correspond to the sample. From the group corresponding to the sixth form there were 1940 written texts from 1940 different subjects. Therefore, the significant sample corresponds to 332 texts. In the case of the secondary group (2076 subjects and texts) the sample was of 335 and in the primary group (1521 subjects and texts), it was 317 texts. Once the minimum size of the samples had been established, there was an increase by $50 \%$ of the amount of the sample from the primary group, as the number of words written by the subjects was significantly smaller in this group than in the other two. Consequently, there were finally 475 texts written by the primary group.

The topic of the texts was different for each of these three groups. The sixth form group wrote a text about natural forces and calamities. This text was part of an official exam students took at the end of their sixth form period. The subjects from the secondary group wrote about an imaginary trip to a location in England, and the primary group wrote a letter providing basic personal information. In these two cases, the texts were part of a test conducted with the students in order to determine their level of communicative competence. 
The texts were transcribed keeping the grammatical mistakes. Later on, the texts were processed in a computer programme ${ }^{2}$, previously created in a word processor together with a database manager which allowed the joint use of the programme and the corpus. The programme allowed the search of lexical forms in the corpus, generating a list with all these forms, and also showing all the texts composing the corpus. When a lexical form is introduced in the search box, all the items corresponding to this form in the corpus will be highlighted. Thus, it is possible to analyze each form in the context in which it appears. For this study, all the thematic verbs were searched and the presence or absence of the variables analyzed were determined. The same procedure was conducted regarding the verb $b e$.

\subsection{Features and variables for the analysis}

The focus of the corpus analysis was set on the verb structures and more specifically on the features of tense and agreement. Hence, the basic elements of analysis were the bound morphemes $-s$ and -ed. The former refers to agreement between an argument (mostly the subject in third person singular) and the verb in present tense, while the latter marks the past tense in the verb. Yet, with the purpose of determining the learning process of verb structures and following Zobl and Liceras (1994), who claim that the acquisition of the suppletive agreement takes place prior to that of these two morphemes, this study also includes the analysis of this agreement through the verb be, both in its copular and auxiliary functions.

The bound morpheme $-s$ is an agreement marker [+agreement] between the verb and an argument. This marker always determines a finite form [+finite]. Besides, it always occurs in the present tense. Therefore it also refers to the feature of tense [past]. For example:

She lives [+finite, -past, +agreement] with her parents.

The bound morpheme -ed is a marker for the feature of tense [+past]. Its presence also determines a finite form [+finite]. It does not require any subject-verb agreement. These features are exemplified as follows:

He arrived [+finite, +past] two days ago.

The absence of these features may occur with finite forms and with verb forms which represent an incorrect grammatical realization:

2 FreconWin (frequencies and contexts); author: José Luis Guerrero Martín (2001). 
(3) They live [+finite, -past, +agreement] with their parents.

(4) *She live with her parents.

(5) *He arrive two days ago.

Nonetheless, the presence of these morphemes is considered incorrect in certain contexts, as shown in the following examples:

(6) *They lives [+finite, -past, -agreement] with their parents.

(7) *He arrived [+finite, + past] tomorrow.

(8) *He arrives [+finite, -past, +agreement] yesterday.

Consequently, the variables for the analysis would be the correct and incorrect uses, as well as the omissions, of these two bound morphemes in contexts where their use is obligatory. An obligatory context would be where a native speaker of English (L1) makes use of the morpheme. In the case of the morpheme $-s$ a context is recognized as obligatory when the morpheme appears bound to a verb in present tense and showing agreement with the corresponding argument in the sentence, as in example (1). The morpheme -ed appears in an obligatory context bound to a verb in past tense, as in example (2).

The free morpheme be also shows the features of tense and agreement. This study will only focus on the present tense [-past]. The three different forms that the verb be can adopt are $a m$, is and are:

(9) I am [+finite, -past, +agreement] Spanish.

(10) She is [+finite, -past, +agreement] English.

(11) They are [+finite, -past, +agreement] students.

In the case of the auxiliary function, the tense and agreement features would be the same:

(12) I am [+finite, -past, +agreement] studying.

(13) She is [+finite, -past, +agreement] playing.

(14) They are [+finite, -past, +agreement] drinking water.

In this case, since it is a free morpheme, the omission would be the absence of the verb form in an obligatory context:

(15) * Spanish.

(16) *She playing. 
Finally, in relation with the incorrect uses of these verb forms in the present tense, we would find the lack of agreement between the verb and the person and number, determined mainly by the subject of the sentence:

*l is [+finite, -past, -agreement] Spanish.

*She are [+finite, -past, -agreement] playing.

Regarding the realizations of the verb be, Ionin and Wexler (2002) have also referred to the overgenerated verb be. This type of realization refers to the use of the verb be accompanying main verbs in an incorrect context:

*He is [+finite, -past, +agreement] work there.

According to these authors, this incorrect use of the verb be aims at giving the components [+finite, +agreement] that the learner has not been able to acquire yet through the verb inflections, and which should appear in the main verb (work). Following their argument, this happens because the acquisition of the verb be is prior to the acquisition of the bound morphemes: "[...] there is evidence that be forms are, in fact, mastered by L2 learners of English prior to suffixal agreement endings" (p. 102).

To sum up, the variables determined for this study, both for the bound and the free morphemes, were: correct uses, incorrect uses and omissions.

\section{Results}

Below, the results for each of these morphemes and the variables used for the analysis are presented.

\subsection{The free morpheme be}

First, with regard to the use of the verb be with a copular function, the percentage of correct use is over $90 \%$ in the three groups. The percentage of incorrect use can be considered insignificant, as it does not exceed $5 \%$ in any of the groups. Also, the number of omissions decreases over these three groups, presenting a percentage of $5.80 \%$ in the primary education group and diminishing to $0.53 \%$ in the sixth form group. 


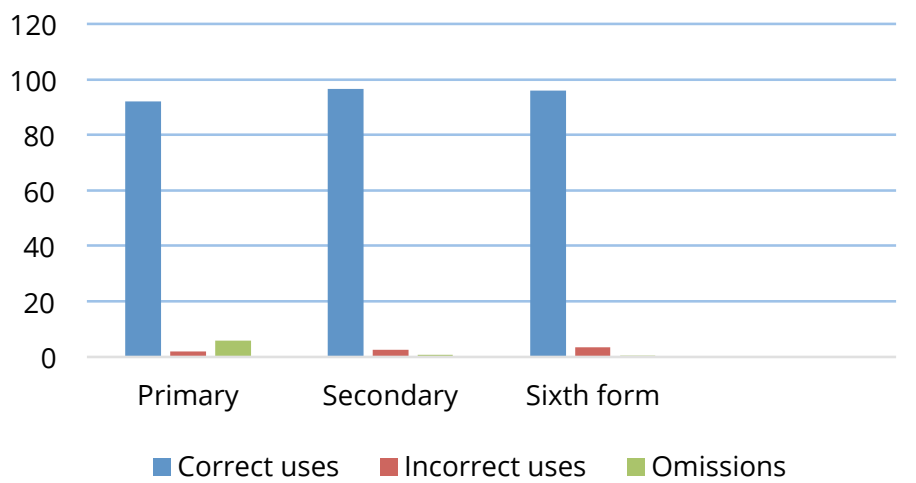

Figure 1. The copular verb be.

The correlation between the correct uses and the variable time is direct $(r=0,772)$. Likewise, the correlation between the incorrect uses and time is also direct $(r=0,957)$. However, the correlation between the omissions and time is inverse $(r=-0,892)$. The correlations between time and both correct uses and omissions show a positive progress in the use of this verb. Notwithstanding, the values of the correlations for these three variables related to time are not statistically significant.

As for the verb be with an auxiliary function, the results show a positive evolution of its use as well, with an increase in the percentage of correct use over the three groups, except for a slight set-back in the sixth-form: $69.23 \%$ in primary education, $80.77 \%$ in secondary education and $78.21 \%$ in sixth form. Hence, the results show both a positive learning and usage of the suppletive agreement by the subjects.

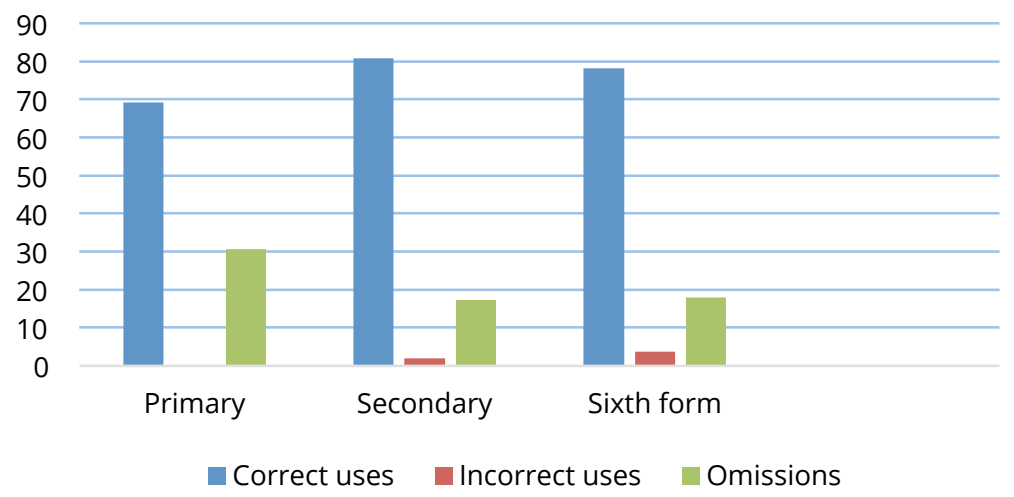

Figure 2. The auxiliary verb be. 
The correlation of the correct uses in this case is also direct $(r=0,741)$ while in the omissions it is inverse $(r=-0,845)$. Despite not being significant, the results in both cases can be associated to a positive progression in the learning process of this structure. Yet, there is a significant perfect direct correlation in the incorrect uses $(r=1,000)$, which shows that the incorrect uses increase with time in this case.

\subsection{The bound morphemes -ed and -s}

The use of the bound morphemes shows different results, however. On the one hand, the analysis of the bound past morpheme -ed reflects a positive learning process of this grammatical structure. The use of this morpheme in the primary education group has not been considered in this analysis, since the number of times it is used (both correctly and incorrectly) is not large enough to draw a conclusion. Following the analysis, the percentage of correct use in the secondary education and sixth form groups is over $80 \%$. The percentage of incorrect use and omission, on the other hand, is very low. Consequently, these results indicate an achievement in the learning process of this structure.

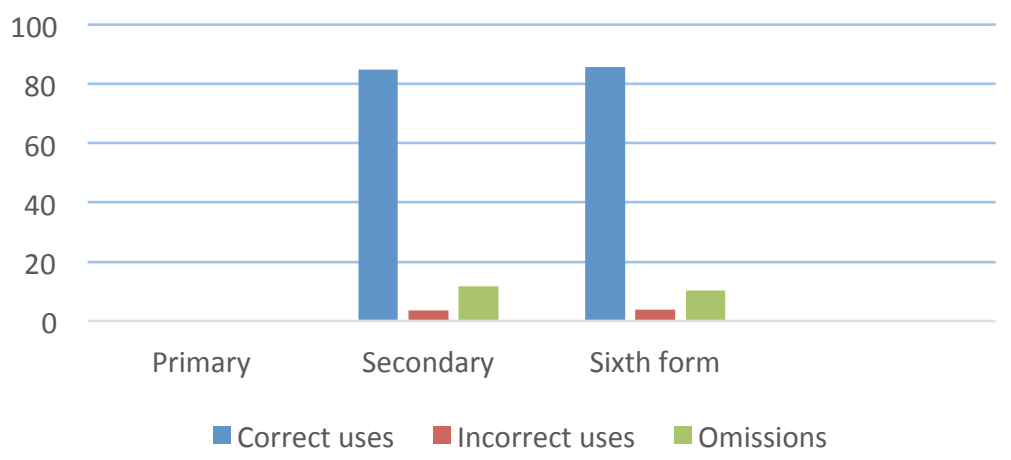

Figure 3. The bound morpheme-ed.

In the case of this morpheme the correlations of the three variables are significant. Regarding the correct uses there exists a perfect direct correlation $(r=1,000)$ which shows a positive relation in the evolution of the correct uses through time. The omissions present a perfect inverse correlation $(r=-1,000)$ manifesting a decrease in further stages in the learning process. Notwithstanding, a perfect direct correlation in the case of the incorrect uses also exhibits an increase as the subjects progress in the educational process $(r=1,000)$.

Yet, the results of the bound morpheme -5 are not as satisfactory. The number of omissions is the highest value in the primary education (41.22\%), secondary 
education (67.27\%) and sixth form (51.87\%) groups. The secondary education group presents lower values in correct use $(21.82 \%)$ than those obtained in the primary education group (23.65\%) and sixth form (40.65\%). The conclusion drawn from the data is that the sixth form group shows the best results for this morpheme. It presents the highest level of correct use (40.65\%) in the three groups, as well as the lowest level of incorrect use (7.48\%). Nevertheless, although there is an improvement in the learning process of this structure over the three groups, this process cannot be considered satisfactorily completed. This is due to the fact that the highest percentage of the three variables for this morpheme in this group corresponds to omissions (51.87\%).

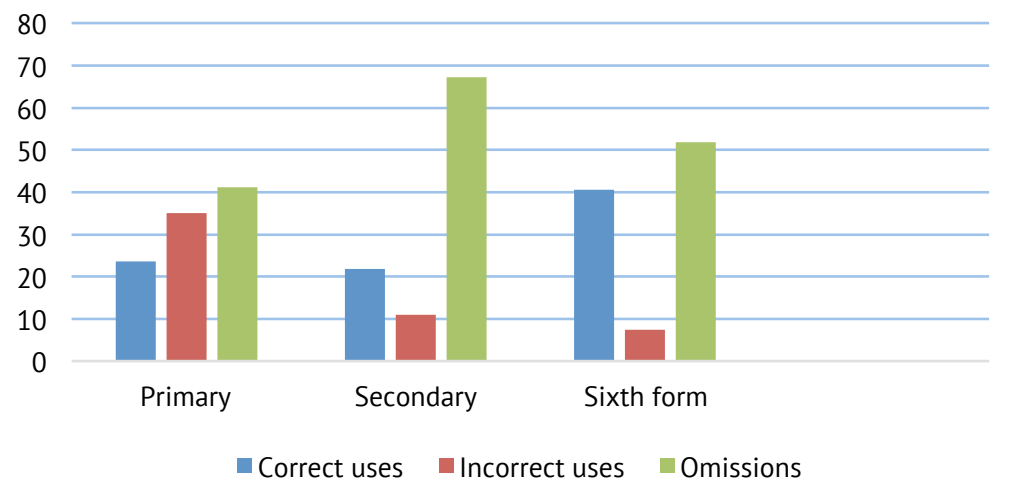

Figure 4. The bound morpheme -s.

The correlations of time and these three variables are not significant. In spite of this, a direct correlation between time and the correct uses $(r=0,819)$ and an inverse correlation between incorrect uses and time $(r=-0,917)$ show positive values in relation with the learning process. Nevertheless, the correlation of omissions and time $(r=0,407)$ also present an increase of this variable throughout the learning process.

\subsection{The overgenerated verb be}

This study also presents an analysis of the structure introduced by lonin and Wexler (2002) defined as overgenerated be, which these authors describe as "a 'substitute' for affixal inflection" (p.119). According to this idea, the increase in the correct use of the thematic verb inflections should be parallel to the decrease in the apparition of the overgenerated be.

Focusing on the results of this structure in the corpus analysed, this decrease occurs, with the highest frequency in the primary education group (42 cases) and the 
lowest in the sixth form (7 cases). The secondary education group presents an intermediate value (16 cases). These higher values found in the initial stages of the learning process agree with the idea presented by Hawkins and Casillas (2008) when they claim that "early learners use a construction not found in input: be + bare V" (p. 610).

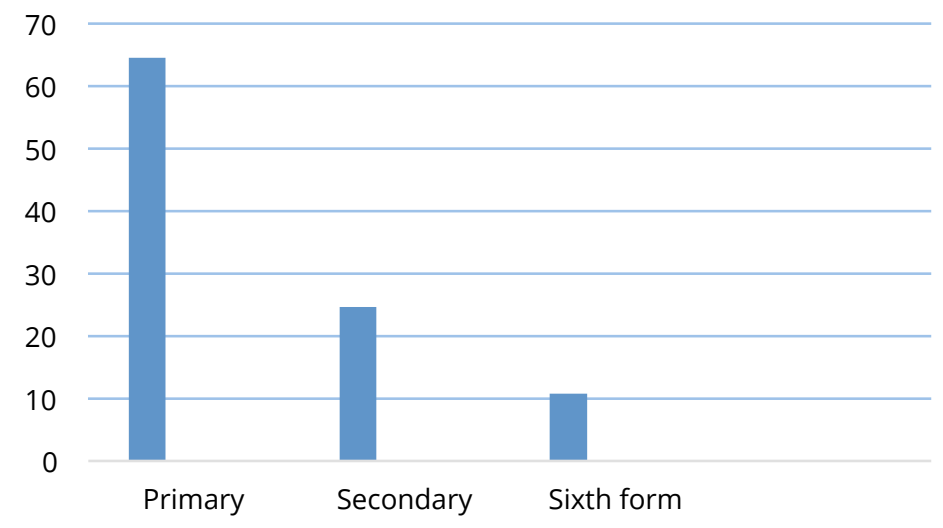

Figure 5. Overgenerated verb be.

In this case, the correlation is not significant. However, it is clear that both variables (the presence of the overgenerated be and time) are in inverse ratio $(r=-0,931)$, that is to say, as the learning process progresses in time the number of appearances of this anomalous use of the verb be decreases.

\subsection{Comparison of correct uses of the free and bound morphemes}

In all, this study can conclude that the subjects have positive values for the use of the verb be, both with copular and auxiliary functions. Furthermore, the use of the bound morpheme -ed for past tense also presents good values in the learning process of this structure. Although the use of the bound morpheme $-s$ does not show the same good values, and this study cannot conclude that there is a positive achievement of the learning process of this structure, the disposition of the values obtained over the three groups reflects a positive trend and an improvement in that learning process. Finally, the decrease in the use of the overgenerated be accompanied by an increase in the use of the bound morphemes over the three groups represent another positive sign in the good result of their L2 learning. The correlations of the correct uses and time are direct regarding the correct uses of all these structures. Therefore, their correct uses increase as the learning progress advances. 


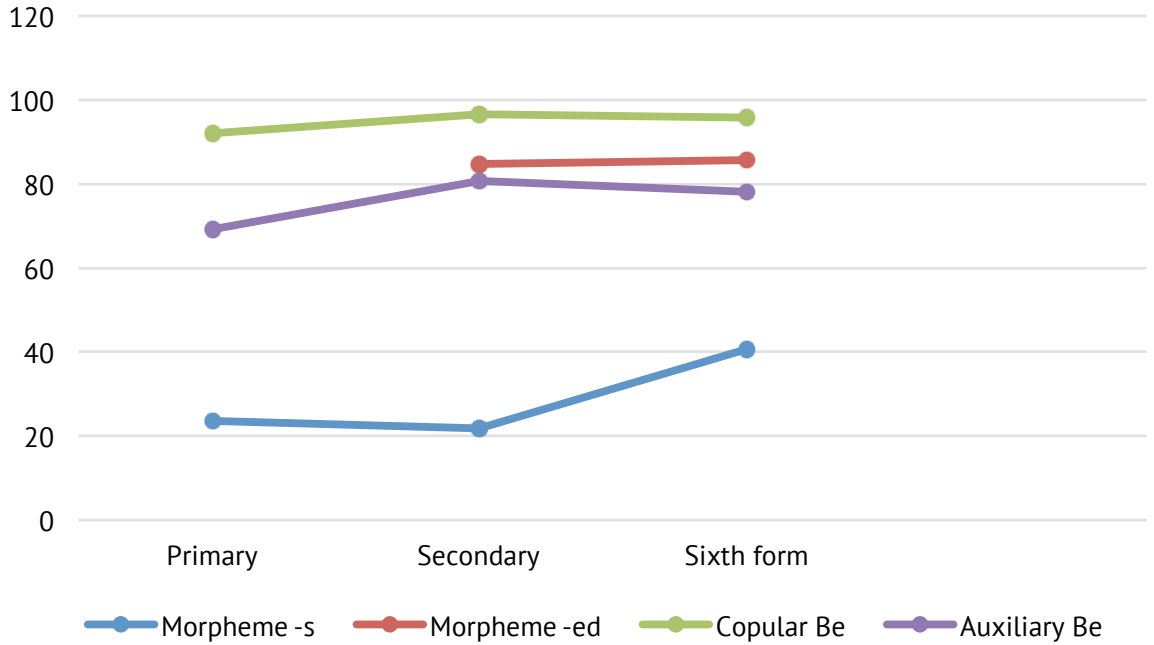

Figure 6. Correct uses in the three groups.

\section{Discussion}

\subsection{Evolution of the learning process}

This study shows unsatisfactory results in the use of the bound morpheme $-s$ which could mean a lack of acquisition of the feature of tense. Nevertheless, the acquisition of the past morpheme -ed is favourable. This means that the acquisition of the past tense is favourable too.

If this study were to conclude that the unfavourable results obtained in the use of the bound morpheme $-s$ mean a failure in the process of acquisition of the present tense, then the conclusion would be that the subjects are more competent in the use of the past tense than the present tense. This assertion would, therefore, imply that the subjects acquire the past tense before the present tense.

On the contrary, these results indicate a difficulty in acquiring the feature of agreement, relating to the agreement between the verb and the third person singular. Nevertheless, the good results in the use of the verb be manifest the acquisition of the suppletive agreement. Therefore, despite the difficulties in the use of the bound morpheme $-s$, this fact cannot lead to the conclusion that there has been no agreement acquisition.

In all, as the acquisition of the free morphemes, and therefore of the (suppletive) agreement, is very satisfactory and so is the acquisition of tense shown by the 
positive results in the use of the bound morpheme -ed, this study can conclude that the learning process of the subjects, measured through the use of tense and agreement features, is satisfactory.

\subsection{Order of acquisition of the morphemes}

In view of the results presented in the previous section, the order of acquisition of the verbal morphemes in this study would be established as follows:

verb be copular > morpheme -ed > verb be auxiliary > morpheme $-s$

This order does not coincide with the one presented by Zobl and Liceras (1994) and Ionin and Wexler (2002) for learners of English as a foreign language:

verb be copular > verb be auxiliary > morpheme $-e d>$ morpheme $-s$

Zobl and Liceras (1994) indicate that the free morphemes have an influence over the bound morphemes and delay the acquisition process: "The free-bound morpheme distinction accounts for the ordering of $L 2$ in that the early presence of free morphemes as exponents of functional projections may delay the acquisition of affixal exponents (bound morphemes)" (p.41).

Hawkins and Casillas (2008) and Haznedar (2003) also refer to competence in the use of the verb be (copular and auxiliary) prior to competence acquired in the use of the bound morphemes $-s$ and -ed. Paradis (2008) refers also to the "precocious acquisition of BE" (p.351) in L2 acquisition.

In his research, Hsieh (2009) did not analyse the verb be in its auxiliary function, but with regard to the free (be copular) and bound morphemes, he reaches the same conclusion: "[...] the forms of copular be are acquired before the inflectional morphology on in situ thematic verbs" (p. 45). However, he described a better performance for the morpheme $-s$ than for the morpheme -ed, relating this fact to "the individual factors and the effect of phonetics in English" (p.57).

On the other hand, these results do not agree with those obtained by Muftah and Eng (2011) with Arab learners of English as an L2. Their study of the verb be auxiliary and the bound morpheme $-s$ shows better results in the acquisition of the bound morpheme, suggesting that "adult Arab ESL learners, even at an ultimate attainment level, are more sensitive to thematic verb contractions than to be auxiliary constructions" (p.91). 
The data presented in the previous section showed very good results for the use of the bound morpheme -ed. Together with its position in the order of acquisition prior to the auxiliary be (due to its higher number of correct uses), this fact contradicts most of the studies described to date.

The secondary education group presents a high percentage of correct use of this morpheme (84.78\%). The percentage of omission (11.74\%) and incorrect use (3.48\%) support the argument in favour of a positive learning of this grammatical structure. In fact, the percentage of correct use is closer to the percentage obtained in the use of the verb be, both copular (96.69\%) and auxiliary (80.77\%), than to the use of the other bound morpheme $(-s)$, which presents a very low percentage of correct use (21.82\%).

Comparing these results with those of the sixth form group, the conclusion obtained is similar to the previous one. Again, the correct use of the morpheme -ed presents the highest percentage $(85.79 \%)$ of the three variables analysed, followed by omission (10.36\%) and incorrect use (3.85\%). These results are also close to the correct use accomplished with the verb be, copular (95.88\%) and auxiliary (78.21\%). In contrast, the percentage of correct use of the bound morpheme -5 (40.65\%) lies far from these results.

There are other factors which could be influencing the satisfactory acquisition of the past morpheme compared to the agreement bound morpheme. O'Grady (2006) designates aspect as a factor which complicates this acquisition: "[...] the computation of aspect creates difficulty for tense marking" (p.182). This statement is related to the Aspect Hypothesis (Bardovi-Harlig, 1998) and the classification of the four aspectual classes proposed by Vendler (1967). Therefore, following this argument, aspect may have had an influence on the results for this morpheme. Nevertheless, to analyse the influence of aspect it is necessary to analyse not only the verb itself, but also the arguments that accompany it, as these determine the aspectual class to which it belongs. As the analysis of aspect has not been a goal in this research, the influence of this factor on the results cannot be determined.

In his study of the acquisition of the past tense by Spanish speakers learning English, Salaberry (2000) concluded that aspect cannot respond to the development of past tense marking. He analysed both the oral and written production of learners. In his results, he obtained better values in written production than in oral production. This agrees with Ellis (1997), who claimed that the morpheme -ed appears more frequently in written than in oral discourse, since planning time affects the use of past tense markers. Nevertheless, these poor results in oral discourse could also be related to the difficulty learners find in pronouncing the consonant clusters formed when adding the ending -ed to the verb. As the corpus that this study has used 
belongs to the subjects' written production, the results may also be influenced by the task, in which case, it would agree with the ideas put forward by Salaberry (2000) and Ellis (1997). To conclude that the results would be different in oral production, it would be necessary to conduct an analysis of a corpus obtained from such production.

Finally, there is another factor that could also influence the use of the past tense forms: the input. In fact, O'Grady (2006) relates aspect to the presence of the verbs in the input: "[...] past tense marking apparently occurs more often in the input on verbs denoting achievements than on those denoting activities" (p.184). The analysis of input as a variable to rate in this research has not been included. However, there can be a relation between this study and this factor to some extent, especially taking into account the educational levels of the subjects and the hours they have spent learning English.

The primary education subjects have been learning English for, at least, six years, with an average number of 3-4 hours per week. The secondary education group have engaged in a learning process for, at least, ten years with the same average number of hours per week. Finally the sixth form subjects have studied English for, at least, twelve years, with an average number of four hours per week.

Therefore, the amount of time that the subjects have been exposed to English increases as they pass from one stage to the other. This increase coincides with an improvement in their competence in the use of the verb morphemes. Ellis (2002) and Goldschneider and DeKeyser (2001) relate the acquisition of the morphological structures to input and not to any innate linguistic knowledge. They specify the salience of the morphological structure as decisive in its acquisition. Hawkins and Casillas (2008) argue against these claims, supporting the idea of an innate linguistic knowledge in the acquisition of these morphological structures. According to them, the retrieval of a morphological structure depends on the number of syntactic nodes necessary to specify the context in which it is going to be inserted.

The number of nodes of the bound morphemes is higher than that of the verb be. This triggers a prior acquisition of the free morphemes. However, as it has already been seen, in this research, the learning of the bound morpheme -ed is prior to the auxiliary be. Therefore, this statement is not enough to explain this order of acquisition.

O'Grady (2006) attests that the verb be is the second most common word in the input, the definite article the being the most common. The verb form is was highly frequent in the corpus of this study, especially in the primary education group. Yet, the definite article is acquired after the verb be in the process of acquisition of English, both as an L1 and an L2. There are even other classifications that place the 
acquisition of this article after the plural morpheme $-\mathrm{s}$ and the morpheme -ing (Zobl and Liceras, 1994). This fact contradicts the idea that the frequency in the input is the only factor determining the acquisition of a grammatical structure.

The influence of the input as a decisive factor in the learning process of these morphemes has not been addressed in this research. Consequently, it would be necessary to conduct a study in which the effect of this factor could be controlled more efficiently to establish its influence on their learning process.

There is another factor to be considered in an explanation of the differences found in the learning process between free and bound morphemes. This factor relates to the type of memory used in the process. O'Grady (2006) relates the acquisition of the free and bound morphemes to the use of declarative or procedural memory.

According to Ullman (2001), procedural memory allows for the development of computations and symbolic manipulations which are associated with what is known as grammar, and which includes syntax, non-lexical semantics, morphology and phonology. On the other hand, we would find declarative memory responsible for the knowledge related to words, including their meaning, pronunciation and use (mental dictionary).

Different authors (Paradis, 2004; Ullman, 2001; 2005) have noted that the ability to use procedural memory decreases as the learner gets older. In the acquisition process of an L1, the learner acquires verb agreement by using procedural memory. However, a subject who starts learning an L2 late in life will have to use declarative memory in order to acquire the grammatical structures which the L1 learner has acquired through procedural memory.

The subjects from this study have conducted their learning process in a classroom context and, therefore, have acquired the use of the morpheme -s using conscious learning and declarative memory. This learning has not been integrated unconsciously in the learner's mind and, accordingly, the realisation of this morpheme shows negative values with regard to its learning process. Besides, all the subjects have started learning English late in life in comparison to the process of acquisition of English as an L1. O'Grady (2006) emphasises this dichotomy in the use of both types of memory as one of the main differences between acquiring an L1 and an L2.

As it has been described before, the task performed by the learners (oral or written) also has an influence on the results of the learning process. A written task reflects better results than an oral task. We could also relate this fact to the use of declarative and procedural memories. The written task implies a conscious process, which is directly related to declarative memory, whereas immediacy, characteristic 
of the spontaneous oral discourse, involves computations determined by procedural memory.

Since this research has been conducted using written production, it is highly probable that the subjects have used their declarative memory in the production of the bound morphemes. This would give rise to bad results in the learning process of these structures. Nevertheless, although the use of the past morpheme -ed also corresponds to the part of the grammar learned through procedural memory, its results are evidently better than the results of the -s morpheme. According to these results, it could be said that two grammatical structures (-ed and $-s$ ) depending on procedural memory show opposite results in their learning process in this study. Thus, arguing that the use of one of these two types of memory is what determines the results obtained is not enough.

This fact could also explain the differences in the results of the free morphemes and the bound morphemes that this study has found. If learners were to store the forms of the verb be as units in the lexicon, they would also use declarative memory to learn them.

Hence, this study finds two grammatical structures that would be learned by means of procedural memory which display diverse results, the values obtained in the use of one of them (-ed) being much better than in the other $(-s)$. Both have been analysed in written production and they also share a low saliency in the input. Consequently, there must be another factor accounting for the difference in the results of the past tense and agreement. Stauble (1984) explains that the highest difficulty when marking the $-s$ in comparison with the -ed has to do with the process of discrimination the learner has to accomplish. All the persons take the inflection ed. However, when marking agreement through the morpheme $-s$, the learner has to identify and do this only with the third person of singular. Therefore, there is no need to discriminate among the different persons when marking the morpheme-ed, which makes this less complicated than marking the morpheme -s.

\subsection{This study and the Missing Surface Inflection Hypothesis}

According to Liceras (2007), "[...] in L2 English, functional projections are available early, instantiated through their lexical exponents (free morphemes) [...]" (p. 41). Thus, competence in the use of the free morpheme be would reflect competence in the Inflection functional category and an achievement in its acquisition. The results of this study coincide with these facts. As it has been seen in previous sections, the results of the verb be are positive in the three groups into which the corpus has been divided. 
The results, therefore, agree with the statements presented by the MSIH. Furthermore, this research also shows similar results to those studies by other authors (Haznedar, 2003; Hsieh, 2009; Ionin and Wexler, 2002; Paradis et al., 2008; White, 2003), who also agree with the arguments presented by the MSIH with regard to the acquisition of functional categories, manifested by the achievement of the features of tense and (suppletive) agreement in the verb be.

As it has been mentioned before, aside from the good results in the use of the verb be, the past morpheme -ed also presents positive results. Thus, the structure which shows the worst results and which could be determined as a sign of impairment in the acquisition of functional categories is the bound morpheme -s. However, the theories that support the idea of impairment refer to the incorrect use of the morpheme (use of finite forms instead of non-finite forms and lack of agreement) as the main proof supporting their ideas.

By observing the progression of the results of the morpheme -5 , it can be confirmed that the data support the ideas put forward by the $\mathrm{MSIH}$ and not by the $\mathrm{IH}$. First, the percentage of incorrect use decreases over the three groups (35.13\% for primary education, $10.91 \%$ for secondary education and $7.48 \%$ for sixth form). Moreover, the percentage of omission is higher than the percentage of incorrect use in the three groups. According to the $\mathrm{MSIH}$, these omissions reflect a problem of $\mathrm{L} 2$ learners relating to performing surface morphology. What is more, this problem does not mean that learners are prevented from acquiring functional categories. Ionin and Wexler (2002) have an explanation for both the acquisition of functional categories and the persistence of difficulties in morphological competence ${ }^{3}$ : "UG principles are fully available in L2 acquisition early on, while parameter-setting takes time" (p. 130). Therefore, this problem with the -5 morpheme would imply problems in the resetting parameters instead of impairment in the acquisition of the functional category.

Nevertheless, despite the fact that the MSIH is compatible with differences in acquisition rates and patterns between inflectional tense morphemes and auxiliaries, as Paradis et al. (2008) indicate, it offers no particular explanation for this phenomenon. Therefore, it is necessary to complete the explanations given by the $\mathrm{MSIH}$ with the factors that determine the morphological phenomena observed.

3 Morphological competence is defined by Liceras (2009: 286) as "the capability of detecting how features are assembled in the second language". 


\section{Conclusions}

Following the results obtained and the discussion presented so far, this study draws several final conclusions. First, the subjects show a positive trajectory in their learning process. The results are on the side of good competence in the use of verbal morphemes, which improves as they move through the levels of the education system. Nevertheless, the use of the two bound morphemes is not parallel. Whereas the analysis of the use of the past morpheme -ed shows very good results, the results of the morpheme $-s$ note a slower learning process for the feature of agreement. However, despite this fact, good competence in the use of the suppletive agreement signifies that the difficulty for the feature of agreement relates exclusively to the bound morpheme and not to the feature itself.

Furthermore, the order of acquisition of the verbal morphemes shows that competence of the bound morpheme -ed is prior to the free morpheme be auxiliary. Nevertheless, as expected, the best results are for the free morpheme be copular and the worst results for the bound morpheme $-s$. The good results obtained in the use of the bound morpheme -ed, especially in comparison with the bound morpheme $-s$, highlight the need to analyse the influence of other factors (input, task, type of memory used, aspect and phonological features) in order to determine the reasons for those results.

Besides, the high percentage of correct use of the free morpheme be (copular and auxiliary) and the predominance of omission, rather than incorrect use in the results of the bound morpheme $-s$, agree with the MSIH (Prévost and White, 2000). Therefore, the subjects accomplish the acquisition of the functional category of Inflection.

Finally, the appearance of the form corresponding to the overgenerated be, and its behaviour over the three groups in the corpus, coincide with the statement given by Ionin and Wexler (2002) determining that its presence compensates for the lack of tense and agreement features in thematic verbs.

\section{LFE About the author}

Jose Medina, Ph.D. in Applied Linguistics from the University of Las Palmas de Gran Canaria (Spain). His main research was focused on the learning process of EFL by Spanish speakers. Currently, he works as a lecturer in the Teacher Training Faculty at the University of Las Palmas de Gran Canaria and as a researcher at the Humboldt Universität zu Berlin. His main research interests revolve around the 
study of the foreign language learning process, as well as content and language integrated learning (CLIL), particularly through his participation as a researcher in the European project playingCLIL.

\section{LFE Article history}

Paper received: $5^{\text {th }}$ March 2015

Paper received in revised form and accepted for publication: $5^{\text {th }}$ May 2015

\section{Bibliographical references}

Albright, A., and Hayes, B. (2003). Rules vs. analogy in English past tenses: a computational/experimental study. Cognition, 90, 119-161.

Andersen, R. W. (1978). An implicational model for second language research. Language Learning, 28, 221-282.

Bardovi-Harlig, K. (1998). Narrative structure and lexical aspect. Studies in Second Language Acquisition, 20, 471-508.

Clahsen, H. (1988). Parameterized grammatical theory and language acquisition: A study of the acquisition of verb placement and inflection by children and adults. In S. Flynn and W. O'Neil (Eds.), Linguistic theory in second language acquisition (pp. 47-75). Dordrecht: Kluwer.

Ellis, N. C. (2002). Frequency effects in language processing: a review with implications for theories of implicit and explicit language acquisition. Studies in Second Language Acquisition, 24, 143-188.

Ellis, R. (1997). Second language acquisition. Oxford: Oxford University Press.

García Ferrando, M. (1985). Introducción a la estadística en sociología. Madrid: Alianza Editorial.

Goldschneider, J.-M., and DeKeyser, R.M. (2001). Explaining the natural order of L2 morpheme acquisition in English: a meta-analysis of multiple determinants. Language Learning, 51, 1-50.

Hawkins, R., and Casillas, G. (2008). Explaining frequency of verb morphology in early L2 speech. Lingua, 118, 595-612. 
Haznedar, B. (2003). Missing surface inflection in adult and child L2 acquisition. In J. Liceras, H., Zobl, and H., Goodluck, (Eds.), Proceedings of the 6th Generative Approaches to Second Language Acquisition Conference (GASLA 2002) (pp. 140-149). Somerville, MA: Cascadilla Proceedings Project.

Hsieh, F. T. (2009). The acquisition of English agreement/tense morphology and copula be by L1-Chinese-speaking learners. In S., Disney, B., Forchtner, W., Ibrahim and N., Millar (Eds.), Papers from the Lancaster University Conference in Linguistics and Language Teaching 3 (pp. 45-59). <http://www.ling.lancs.ac.uk/pgconference/v03.htm> [15/01/2015]

Ionin, T., and Wexler, K. (2002). Why is ' is ' easier than '-s ?: acquisition of tense/agreement morphology by child second language learners of English. Second Language Research, 18, 95-136.

Kim, K. (2011). Overgenerated be from topic marker to verbal inflection. In L., Plonsky and M., Schierloh (Eds.), Selected proceedings of the 2009 second language research forum (pp. 7081). Somerville, MA: Cascadilla Proceedings Project.

Liceras, J. M. (2007). A "linguistic approach" to the idiosyncratic nature of second language acquisition: Monosyllabic place-holders and morpheme orders. Bilingualism: Language and Cognition, 10, 39-41.

Liceras, J. M. (2009). On parameters, functional categories and features ... and why the trees shouldn't prevent us from seeing the forest ... Second Language Research, 25(2), 279-289.

Meisel, J. (1991). Principles of Universal Grammar and strategies of language learning: some similarities and differences between first and second language acquisition. In L., Eubank (Ed.), Point counterpoint: Universal Grammar in the second language (pp. 231-276). Amsterdam: John Benjamins.

Meisel, J. (1997). The acquisition of the syntax of negation in French and German: contrasting first and second language development. Second Language Research, 13, 227-263.

Muftah, M. Y. A., and Eng, W. B. (2011). The acquisition of English be auxiliary and thematic verb constructions by adult arab ESL learners. International Journal of English Linguistics, $1(2), 91-105$.

Neuber, K. A. (1980). Needs Assessment. A model for community planning. Newbury Park: SAGE Publications.

O'Grady, W. (2006). The problem of verbal inflection in second language acquisition. $<$ http://www.ling.hawaii.edu/faculty/ogrady/Verbal_inflection_in_SLA.pdf $>$ [20/01/2015]

Paradis, J. (2008). Tense as a clinical marker in English L2 acquisition with language delay/impairment. In E., Gavruseva and B., Haznedar, (Eds.), Current Trends in Child 
Second Language Acquisition: A Generative Perspective (pp. 337-356). Amsterdam: John Benjamins.

Paradis, J. (2010). Bilingual children's acquisition of English verb morphology: Effects of language exposure, structure complexity, and task type. Language Learning, 60(3), 651680.

Paradis, J., Rice, M., Crago, M., and Marquis, J. (2008). The acquisition of tense in English: Distinguishing child second language from first language and specific language impairment. Applied Psycholinguistics, 29, 689-722.

Paradis, M. (2004). A neurolinguistic theory of bilingualism. Amsterdam: John Benjamins.

Prévost, P., and White, L. (2000). Missing surface inflection or impairment in second language acquisition? Evidence from tense and agreement. Second Language Research, 16, 103-133.

Salaberry, M. R. (2000). The acquisition of English past tense in an instructional setting. System, $28,135-152$.

Selinker, L. (1972). Interlanguage. International Review of Applied Linguistics, 10, 209-231.

Stauble, (1984). A comparison of a Spanish-English and a Japanese-English second language continuum: Negation and verb Morphology. In R. W. Andersen (Ed.), Second Languages: A cross-linguistic perspective (pp. 323-353). Rowley, MA: Newbury House.

Ullman, M. (2001). The neural basis of lexicon and grammar in first and second language: The declarative/procedural model. Bilingualism: Language and Cognition, 4, 105-122.

Ullman, M. (2005). A cognitive neuroscience perspective on second language acquisition: The declarative/procedural model. In C. Sanz (Ed.), Mind and context in adult second language acquisition (pp. 141-178). Washington, DC: Georgetown University Press.

Vendler, Z. (1967). Linguistics in philosophy. Ithaca, NY: Cornell University Press.

White, L. (2003). Fossilization in steady state L2 grammars: Persistent problems with inflectional morphology. Bilingualism: Language and Cognition, 6(2), 129-141.

Zobl, H., and Liceras, J. (1994). Functional categories and acquisition orders. Language Learning, 44, 159-180. 